\title{
Retraction notice for: "Effect of IncRNA HULC knockdown on rat secreting pituitary adenoma GH3 cells" [Braz J Med Biol Res (2019) 52(4): e7728]
}

\author{
Qiu Hong Rui(i) ${ }^{1}$, Jian Bo Ma(i) ${ }^{1}$, Yu Feng Liao (i) ${ }^{1}$, Jin Hua Dai (ii) ${ }^{1}$, and Zhen Yu Cai (i) ${ }^{2}$ \\ ${ }^{1}$ Department of Clinical Laboratory, HwaMei Hospital, University of Chinese Academy of Sciences (Ningbo No. 2 Hospital), \\ Ningbo, Zhejiang, China \\ ${ }^{2}$ Department of Pain Clinic, The First Affiliated Hospital of Xiamen University, Fujian Medical University, Xiamen, Fujian, China
}

Retraction for: Braz J Med Biol Res | doi: 10.1590/1414-431X20197728 | PMID: 30994730 | PMCID: PMC6472935

The Brazilian Journal of Medical and Biological Research received a request from the authors to withdraw this manuscript. Meanwhile, the Editors became aware of a denouncement published by independent journalists from the "For Better Science" website including this paper. This denouncement consisted of potential data falsification and/or inaccuracy of results in western blots and flow cytometry plots.

As per consensus between the Authors and the Editors-in-Chief of the Brazilian Journal of Medical and Biological Research (BJMBR), the article titled "Effect of IncRNA HULC knockdown on rat secreting pituitary adenoma GH3 cells" that was published in year 2019, volume 52, issue 4, (Epub Apr 15, 2019) has been retracted. 


\title{
Effect of IncRNA HULC knockdown on rat secreting pituitary adenoma $\mathrm{GH} 3 \mathrm{e}$ !ls
}

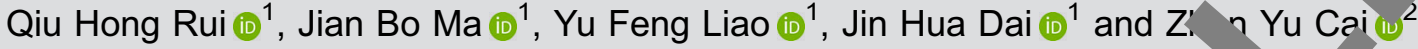 \\ ${ }^{1}$ Department of Clinical Laboratory, HwaMei Hospital, University of Chinese Academy of Sciences .ivbo No. sspital), \\ Vingbo, $>$ ejiang, China \\ ${ }^{2}$ Department of Pain Clinic, The First Affiliated Hospital of Xiamen University, Fujian Medical Univers. Xiamer Fujian, China
}

\begin{abstract}
Pituitary adenoma is one of the most common tumors in the neuroendocrine system is study stigated the effects of long non-coding RNAs (IncRNAs) highly up-regulated in liver cancer (HULC) on rat sf etir pituitary adenoma GH3 cell viability, migration, invasion, apoptosis, and hormone secretion, as well as the underlyir ote chanisms. Cell transfection and qRT-PCR were used to change and measure the expression levels of HULC, miR $\mathrm{b}$, and FOXM1. Cell viability, migration, invasion, and apoptosis were assessed using trypan blue staining assay MTT assa, "wo-chamber transwell assay, Guava

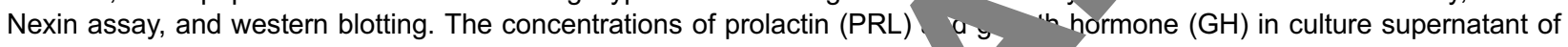
$\mathrm{GH} 3$ cells were assessed using ELISA. The targeting relationship betwee $r$ - $130 \mathrm{~b}$ and FOXM1 was verified using dual luciferase activity. Finally, the expression levels of key factors involved in Pl. AKT/mTOR and JAK1/STAT3 pathways were evaluated using western blotting. We found that HULC was highlvexpressed in $\mathrm{BH} 3$ cells. Overexpression of HULC promoted GH3 cell viability, migration, invasion, PRL and GH secretion, a velr ctivated PI3K/AKT/mTOR and JAK1/STAT3 pathways. Knockdown of HULC had opposite effects and induced cell a ntosis. I LC negatively regulated the expression of miR-130b, and miR-130b participated in the effects of HULC on GH 3 ells. PXM vas a target gene of miR-130b, which was involved in the regulation of GH3 cell viability, migration, invasion, $d$ apopto s well as PI3K/AKT/mTOR and JAK1/STAT3 pathways. In conclusion, HULC tumor-promoting roles in secretir bitu adenoma might be via down-regulating miR-130b, up-regulating FOXM1, and activating PI3K/AKT/mTOR and JAK' STh, oathy ys.
\end{abstract}

Key words: Secreting pituitary adenoma; Lnc Nh iqhly up-regulated in liver cancer (HULC); MicroRNA-130b; Forkhead box protein M1; PI3K/AKT/mTOR signaling pathway; JA. 'STAT3 signaling pathway

\section{Introduction}

Pituitary adenoma, charactorized by liferation of pituitary gland cells tumors in the neuroendocrine s te $(1, L)$. Pituitary adenomas can be divided sec ing and non-secreting pituitary adenomas ( 3 , ine linica ymptoms of secreting pituitary adenoma ar of the endocrine system, such as decreas libia nfertility, galactorrhea, and neurologic compre $n$ (like $h$ daches and visual changes) (4). With the deve. ment of diagnostic and therapeutic methods 5 -year su ival rate of patients with secreting pituitar ade ma has increased in recent years $(5,6)$. Howeve side $g$ that the pathogenesis of this tumor is $\mathrm{vf} \mathrm{mpl},-$ ), a clearer understanding of the process il b helpfur tor defining more effective diagnostic and strategies.

ng non-coding RNAs (IncRNAs) have been proved to exu critical regulatory roles in many biological processes, including cell proliferation, differentiation, and apoptosis (9). Aberrant expressions of IncRNAs have been linked to many human diseases, including secreting pituitary adenomas $(10,11)$. As one kind of IncRNAs, highly up-regulated in liver cancer (HULC) is a key regulatory molecule that participates in the development and progression of hepatocellular carcinoma (12). Some studies in recent years demonstrated that HULC was also involved in the occurrence and development of other human cancers, such as osteosarcoma (13), epithelial ovarian carcinoma (14), bladder cancer (15), glioma (16), breast cancer (17), and chronic myeloid leukemia (18). However, there is no information available about the effects of HULC on pituitary adenoma, including secreting pituitary adenoma.

Similar to IncRNAs, microRNAs (miRNAs) also have important functions in the regulation of multiple cellular biological processes (19). Furthermore, IncRNAs can exert oncogenic or tumor suppressive roles by regulating

Correspondence: Jin Hua Dai: <daijinhua418@sina.com> | Zhen Yu Cai: <fangpoji7015mad@163.com> 
the expressions of miRNAs in cells (20). miRNA-130b (miR-130b) has been shown to participate in cell proliferation and metastasis in many cancer cell lines (21). Leone et al. (22) reported that miR-130b was downregulated in secreting pituitary adenoma.

Forkhead box protein M1 (FOXM1) is a typical cell proliferation-associated transcription factor, which stimulates cell proliferation by promoting S-phase and M-phase entries in cell cycle transition (23). Several reports provide evidence that the expression of FOXM1 is up-regulated in a variety of cancer cells (24). Many miRNAs can modulate the expression of FOXM1 in cancer cells $(25,26)$. However, the role of FOXM1 in the regulation of secreting pituitary adenoma cell proliferation remains unclear.

Hence, in this research, we aimed to explore the effects of HULC on rat secreting pituitary adenoma $\mathrm{GH} 3$ cell line viability, migration, invasion, apoptosis, and hormone secretion, as well as miR-130b expression. The regulatory effect of miR-130b on FOXM1 expression in $\mathrm{GH} 3$ cells and regulatory roles of FOXM1 in $\mathrm{GH} 3$ cell viability, migration, invasion, and apoptosis were also investigated. Our findings will be helpful for further understanding the pathogenesis of secreting pituitary adenoma and provide potential diagnostic and therapeutic targets for secreting pituitary adenoma.

\section{Material and Methods}

\section{Cell lines}

Rat secreting pituitary adenoma cell human embryonic kidney cell line HEK293 were c ined and authenticated by American Type curture Collection (ATCC, USA, Cat. No. CCL-82.1 and C L-1573' Cells were grown in Dulbecco's modified Eagle medi) (DMEM, Gibco, Life Technologies Corpcration, Un splemented with $15 \%(\mathrm{v} / \mathrm{v})$ fetal serum albur $1 \%(v / v)$ penicillin-streptomycin- 9 r ne r00X, Gibco, Life Technologies, USA). Cu we naintained in a humidified incubator (San, Ja an) a $37^{\circ} \mathrm{C}$ with $5 \% \mathrm{CO}_{2}$. Transforming growt Aldrich, USA) w use $s$ an inducer of cell migration and invasion

\section{Isolation rat pituitu y primary cells}

Thr $\mathrm{m}$. Wistar rats (4 weeks, $124 \pm 12 \mathrm{~g}$ ) were obtaine $\mathrm{s}$ andong Laboratory Animal Center $(C$ Ra "e acclimated in a temperature-controlled id s cific puthogen-free environment for 4 days. Then, col acrificed and the pituitary tissues were collec. on ice. Subsequently, pituitary tissues were cut and trypsin, Led. The pituitary primary cells were collected by centrifugation ( $800 \mathrm{~g}$, room temperature, $5 \mathrm{~min}$ ).

\section{Cell transfection}

Short-hairpin RNA directed against HULC and FOXM1 were ligated into U6/GFP/Neo plasmid (GenePharma
Corporation, China) and referred to as sh-HULC and sh-FOXM1. The plasmid carrying a non-targeting s juence was used as negative control (NC) and refe $d t$ as sh-NC. The full-length sequences of HULC were constructed in pcDNA3.1 plasmid (Gen, sar $i$ Corporation) and referred to as pc-HUL $\curvearrowright$ and pc-Fo $\sqrt{ } 11$. The empty pcDNA3.1 plasmid acted as 1 and ref red to as pcDNA3.1. miR-130b mimic, miP $\mathrm{b}$ in to and their NC were designed and synthesi d by Life Itchnologies Corporation. The sequence of $s$ JULC $i$ s 5'-AACCTC CAGAACTGTGATCCA-3'. T se were 5'-GCACAAGAACA AC TA-3' (sense) and 5'-TA CAGTAGTGTTCTTGT' -3 ' (antise). The sequences of miR-130b mimic vide CUCUUUCCCUGUUGCAC UACU-3' (sense) ' 5'-UAG SAACAGGGAAAGAGUU U-3' (antisense' , he equence of miR-130b inhibitor was 5'-AGUAGUG A' AAAGAGU-3'. The sequence of NC of miR-1 mimic and miR-130b inhibitor was 5'-UCA CCUCO IGAAAGAGUAGA-3'. Cell transfection $w$ co using lipofetamine 3000 reagent (Invitrogen , $\supset$ A) for $24 \mathrm{~h}$. Transfection efficiencies of sh-HULC, pi JULC, miR-130b mimic, and miR-130b inhibvere verried using quantitative reverse transcription (qR $\mathrm{CR}$ ). Transfection efficiencies of pc-FOXM1 and shFOXN were verified using qRT-PCR and western blotting.

\section{QR.-PCR}

qRT-PCR was performed to detect the expression levels of HULC, miR-130b, and FOXM1 in GH3 cells after relevant transfection. Briefly, total RNAs in $\mathrm{GH} 3$ cells were isolated using TRIzol ${ }^{\mathrm{TM}}$ Plus RNA Purification kit (Invitrogen). The cDNA was reversely transcribed using high capacity cDNA reverse transcription kit (Applied Biosystems, USA). Then, the expression levels of HULC and FOX $\mathrm{M} 1$ were measured using TaqMan $^{\mathrm{TM}}$ real-time PCR master mix (Applied Biosystems). The expression level of miR-130b was measured using TaqMan ${ }^{\mathrm{TM}}$ non-coding RNA assay (Applied Biosystems). The expression levels of $\beta$-actin and U6 acted as endogenous controls. Data were quantified by $2^{-\triangle \triangle C t}$ method (27). The primer sequences of HULC were 5'-ACCTCCAGAACTGTGATCCAAAATG-3' (sense) and $5^{\prime}$-TCTTGCTTGATGCTTTGGTCTG-3' (antisense). The primer sequence of miR-130b was $5^{\prime}$-ACACTCCAGCT GGGACTCTTTCCCTGTTGC-3'. The primer sequences of FOXM1 were 5'-TCCAGAGCATCATCACAGCG-3' (sense) and 5'-TGCTCCAGGTGACAATTCTCC-3' (antisense). The primer sequences of $\beta$-actin were $5^{\prime}$-GAGAGGGAA ATCGTGCGTGAC-3' (sense) and 5'-CATCTGCTGGAAG GTGGACA-3' (antisense). The primer sequences of U6 were 5'-CAAATTCGTGAAGCGTT-3' (sense) and 5'-TG GTGTCGTGGAGTCG-3' (antisense).

\section{Cell viability assay}

Cell viability was assessed using trypan blue staining assay kit (Beyotime Biotechnology, China) and 3-(4, 5-dimethylthiazol-2-yl)-2,5-diphenyltertrazolium bromide 
tetrazolium (MTT) assay (Sigma-Aldrich). For trypan blue staining, after relevant transfection, $\mathrm{GH} 3$ cells were seeded into a 6 -well plate (Thermo Fisher Scientific, USA) with $1 \times 10^{5}$ cells per well and cultured at $37^{\circ} \mathrm{C}$ for $24 \mathrm{~h}$. Then, cells were collected, washed with phosphate-buffered saline (PBS), stained using the kit solution, and counted under a microscope (Nikon, Japan). Cell viability (\%) was calculated by number of viable cells / number of total cells $\times 100 \%$.

For the MTT assay, after relevant transfection, GH3 cells were seeded into a 96-well plate (Thermo Fisher Scientific) with $1 \times 10^{4}$ cells per well and cultured at $37^{\circ} \mathrm{C}$ for $24 \mathrm{~h}$. Then, $20 \mu \mathrm{L}$ MTT solution $(2.5 \mathrm{mg} / \mathrm{mL}$ in PBS) was added into the medium of each well and the plate was incubated at $37^{\circ} \mathrm{C}$ for $4 \mathrm{~h}$. Subsequently, the MTT mixture was removed and $150 \mu \mathrm{L}$ dimethyl sulfoxide (DMSO) was added to dissolve formazan. After that, the plate was agitated on a shaker for $15 \mathrm{~min}$. The absorbance of each well at $570 \mathrm{~nm}$ was recorded using a microplate reader (Bio-Tek Instrument, USA).

\section{Cell migration and invasion assay}

Cell migration was determined using a modified twochamber transwell assay (Corning Incorporated, USA) Briefly, after relevant transfection, $1 \times 10^{3} \mathrm{GH} 3$ cells were suspended in $200 \mu \mathrm{L}$ serum free-DMEM and adder' ito the upper chamber. Complete DMEM $(600 \mu \mathrm{L})$ was dde into the lower chamber. After incubation at $37^{\circ} \mathrm{C}$ fo, cells were immediately fixed with $4 \%$ parafo raldehy solution (Beyotime Biotechnology, China n, nonmigrated cells in the upper chamber were remov carefully using a cotton swab and migrate culs in the ruwer chamber were counted under a micros ope (Ni n, Japan). Cell migration (\%) was calculated by verage lumber of migrated cells in transfection aroup / av number of migrated cells in control group

Cell invasion was evaluatec ir arry with cell migration, except that the tr ell $n$ nbrane was pre-incubated using Matrigel $\triangle \mathrm{Bi}$,cienc $s$, USA). Cell invasion (\%) was calculated umber of invaded cells in transfection gr ap / a age number of invaded cells in control group $\cap 0 \%$.

\section{Cell apo' osis assay}

Gu a N assay (Millipore Billerica, USA) was used to detec apo sis of GH3 cells. Briefly, after relevant tr tion, cells were seeded into a 6-well plate with $\times 15$ cells ver well and cultured at $37^{\circ} \mathrm{C}$ for $24 \mathrm{~h}$. Then, "llected, washed with PBS, stained using the kit son n, and subjected to flow cytometry analysis (Guava easyc , ie 8HT, Millipore Billerica, USA). Data were analyzed using FCS Express software (De Novo software, USA).

\section{Enzyme linked immunosorbent assay (ELISA)}

ELISA was conducted to measure the concentrations of prolactin (PRL) and growth hormone $(\mathrm{GH})$ in culture supernatant of $\mathrm{GH} 3$ cells. Briefly, after relevant transfection, GH3 cells were seeded into a 6 -well plate y $1 \times$ $10^{5}$ cells per well and cultured at $37^{\circ} \mathrm{C}$ for $24 \mathrm{~h}$ ner the cell supernatant of each group was collected c icen trations of $\mathrm{PRL}$ and $\mathrm{GH}$ were measured using $\mathrm{P}$ ELISA kit and rat GH ELISA kit (Invitroren), respec.

\section{Dual luciferase activity assay}

The $3^{\prime}$ untranslated region ( $\left.R, 2257-304, \mathrm{bp}\right)$ fragment of FOXM1, containing the pi licted $m$-130b binding site, was amplified by PCR d ed in pmirGLO vector (Promega, USA) to orm XMT-wild type (FOXM1wt). To mutate the pr ted mik $20 \mathrm{~b}$ binding site, the predicted binding site was placed, amplified, and constructed in pmirG rector to rm FOXM1-mutated type (FOXM1-mt). Tr sec ence of FOXM1-wt was 5'-CAAAG GCAAUGGUC A $\mathrm{A}-3^{\prime}$ and the sequence of FOX M1-mt was $5^{\prime}-$ AAGGCAAUGGUGACAGUUAAU-3'. Then, $\mathrm{m} 2 \mathrm{nb} \mathrm{mi}$. and reporter vectors were transfected in $\mathrm{H} \longrightarrow$ cells simultaneously. The relative luciferase a y was detected using dual-luciferase reporter assay syste. (Promega).

\section{Wes. n blotting}

W tern blotting was performed as previously des(28). Briefly, total proteins in $\mathrm{GH} 3$ cells were isolated using RIPA lysis buffer (Beyotime Biotechnology, China) ontaining protease inhibitors (Roche, Switzerland) and quantified using BCA protein assay kit (Beyotime Biotechnology). Then, proteins in equal concentrations were electrophoresed in polyacrylamide gels and transferred onto nitrocellulose membranes (Millipore, USA). All primary antibodies were prepared in $1 \%$ bovine serum albumin (BSA, Beyotime Biotechnology) solution at a dilution of $1: 1000$. After incubation with $5 \%$ BSA at room temperature for $1 \mathrm{~h}$, the membranes were incubated with primary antibodies against E-cadherin (ab1416), N-cadherin (ab18 203), Vimentin (ab137321), Snail (ab53519), poly ADPribose polymerase (PARP, ab32138), cleaved-PARP

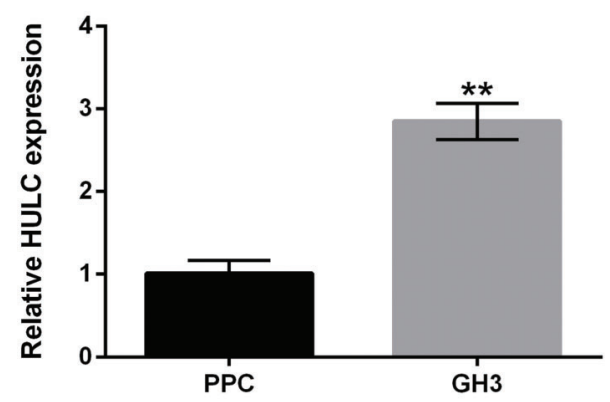

Figure 1. Highly up-regulated in liver cancer (HULC) was highly expressed in $\mathrm{GH} 3$ cells. The expression level of HULC in rat pituitary primary cells (PPC) and rat secreting pituitary adenoma GH3 cells was detected using qRT-PCR. Data are reported as means $\pm \mathrm{SD}$. ${ }^{* *} \mathrm{P}<0.01$ (ANOVA). 
(ab32064), Pro-caspase 3 (ab4051), cleaved-caspase 3 (ab49822), Pro-caspase 9 (ab2013), FOXM1 (ab180 710), p-phosphatidylinositol 3-kinase (PI3K, ab182651), t-PI3K (ab191606), p-protein kinase 3 (AKT, 38449), t-AKT (ab8805), p-mammalian target of rapamycin (mTOR, ab137133), t-mTOR (ab2732), $\beta$-actin (ab8226, Abcam
Biotechnology, USA), p-janus kinase 1 (JAK1, \#74129), t-JAK1 (\#3344), p-signal transducing activator transcription 3 (STAT3, \#9145), t-STAT3 (\#9139), an clez'edcaspase 9 (\#9507, Cell Signaling Technolos $\left(V^{\prime} A\right) a^{+}$ $4^{\circ} \mathrm{C}$ overnight. Then, the membranes were incub $\mathrm{d} v$ goat anti-rabbit (or anti-mouse) IgG H\&L(HRP) seco. ary
A

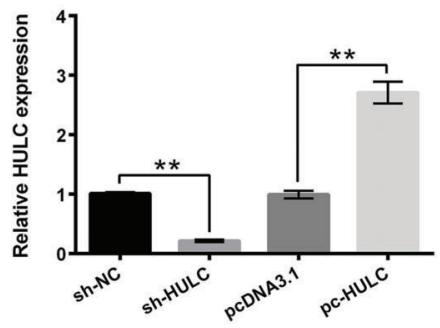

B

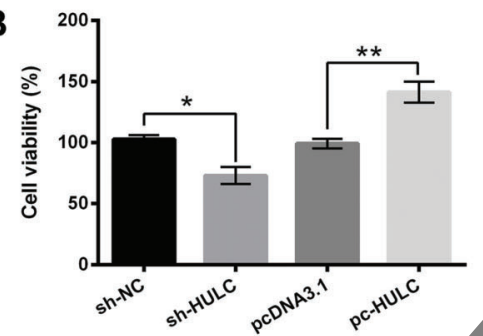

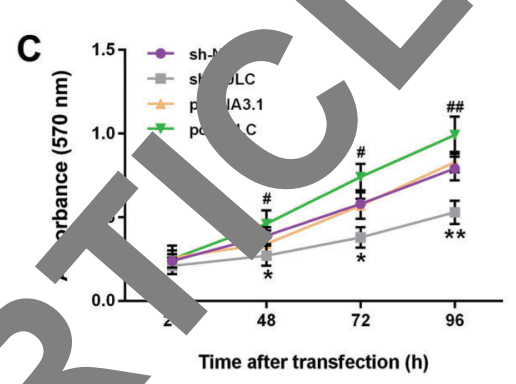

D
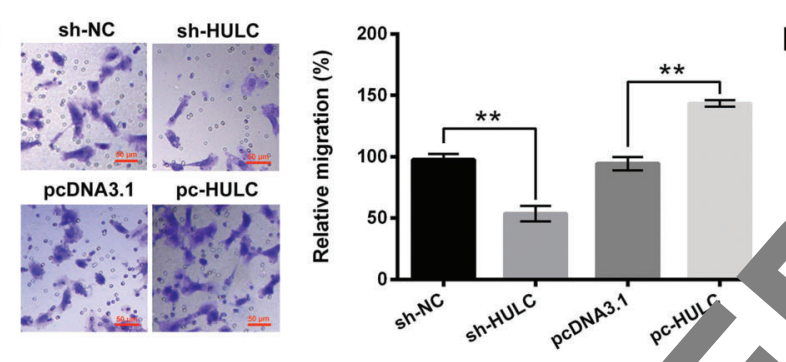

E
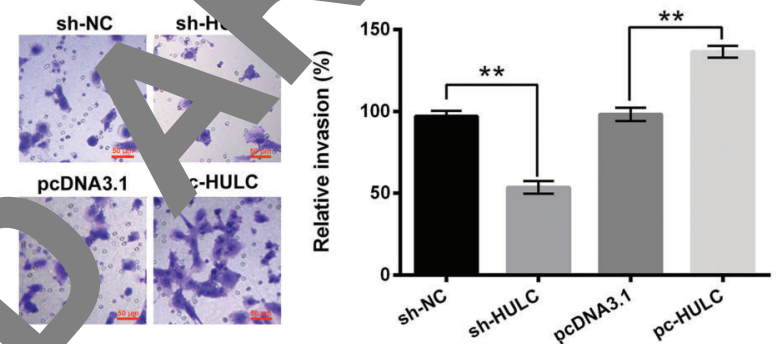

$\mathbf{F}$
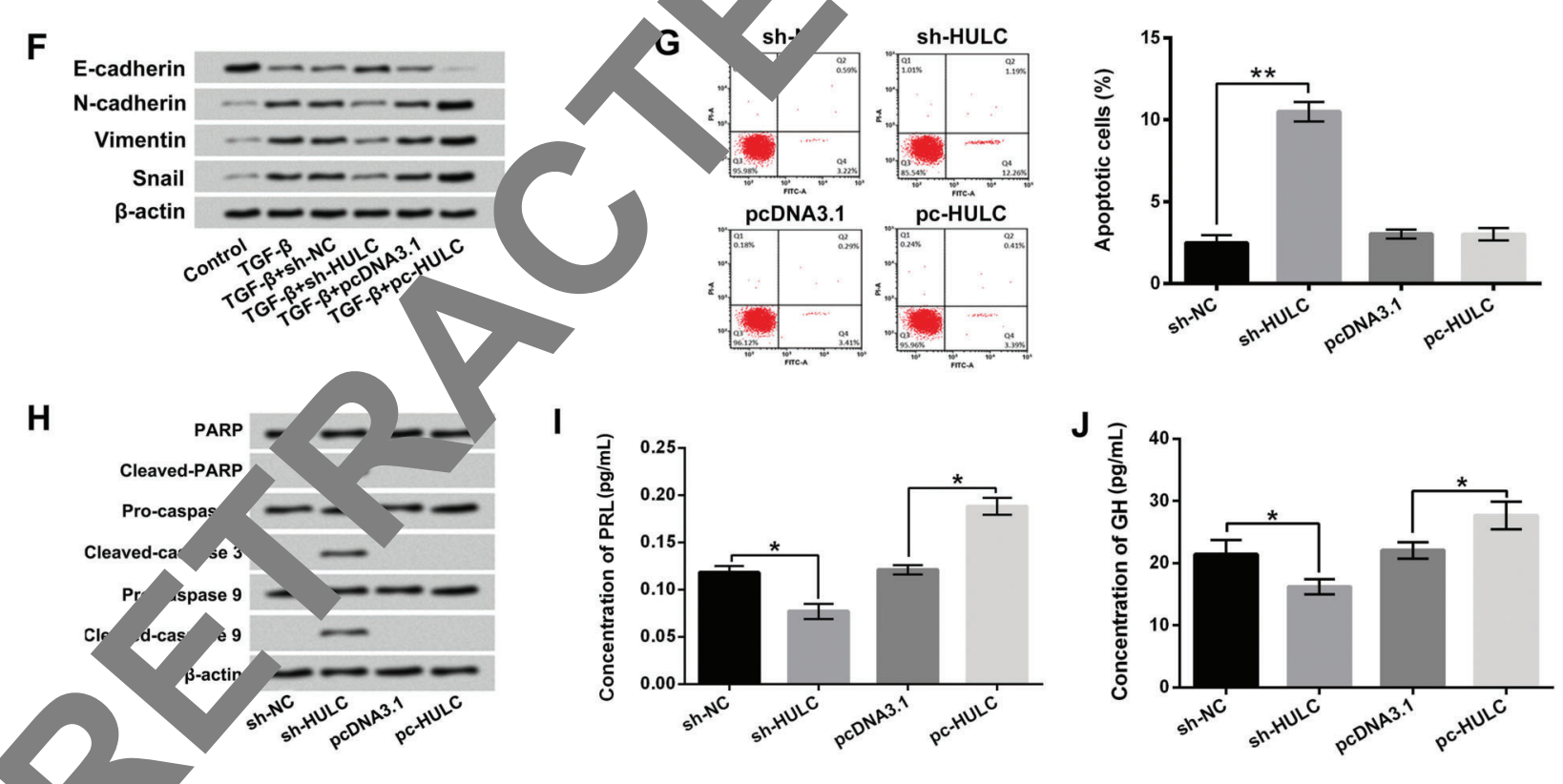

Fig 2. Highly up-regulated in liver cancer (HULC) exerted oncogenic roles in GH3 cells. After sh-HULC or pc-HULC transfection, A, the pression of HULC in GH3 cells, B-E, the viability, migration, and invasion of GH3 cells, F, the expression levels of E-cadherin, $\mathrm{N}$-cadherin, vimentin, and snail in $\mathrm{GH} 3$ cells, G, the apoptosis of $\mathrm{GH} 3$ cells, $\mathbf{H}$, the expression levels of PARP, cleaved-PARP, pro-caspase 3, cleaved-caspase 3, pro-caspase 9 , and cleaved-caspase 9 in GH3 cells, and I and $\mathbf{J}$, the concentration of prolactin $(\mathrm{PRL})$ and growth hormone $(\mathrm{GH})$ in culture supernatant of $\mathrm{GH} 3$ cells were assessed using qRT-PCR, trypan blue staining assay, MTT assay, two-chamber transwell assay, Guava Nexin assay, western blotting, and ELISA. NC: negative control; TGF- $\beta$ : transforming growth factor $\beta$; PARP: poly ADP-ribose polymerase. Data are reported as means \pm SD. ${ }^{*} \mathrm{P}<0.05$, ${ }^{* *} \mathrm{P}<0.01$, ${ }^{\#} \mathrm{P}<0.05$, ${ }^{\# \#} \mathrm{P}<0.01$ compared to pcDNA3.1 group (ANOVA). 
antibodies (ab205718, ab205719, Abcam Biotechnology) for $1.5 \mathrm{~h}$ at room temperature. Followed by adding $200 \mu \mathrm{L}$ Immobilon western chemiluminescent HRP substrate (Millipore) to the surfaces of membranes, the signals of proteins were captured using Bio-Rad ChemiDoc ${ }^{\text {TM }}$ XRS system (Bio-Rad Laboratories, USA). Intensities of bands were quantified using Image Lab ${ }^{T M}$ software (Bio-Rad Laboratories).

\section{Statistical analysis}

All experiments were conducted at least three times. Results of multiple experiments are reported as means \pm SD. Graphpad 6.0 software (Graphpad, USA) was used for statistical analysis. $P$ values were calculated using one-way analysis of variance (ANOVA). Statistically significant differences were set at $\mathrm{P}<0.05$.

\section{Results}

\section{HULC was highly expressed in GH3 cells}

Firstly, we detected the expression level of HULC in rat pituitary primary cells and rat secreting pituitary adenoma $\mathrm{GH} 3$ cells. The results in Figure 1 show that HULC was highly expressed in $\mathrm{GH} 3$ cells, compared to rat pituitary primary cells $(P<0.01)$. This finding suggested that HUIC might exert oncogenic roles in secreting pituitary aden ra.

\section{HULC exerted oncogenic roles in GH3 cells}

Figure 2A shows that the expression ley of $\mathrm{H}$ was significantly decreased after sh-HUI sfection $(P<0.01)$ and increased after pc-HULC tran tion $(P<0.01)$. Figure $2 B-E$ shows that $k$ judown of $F . J L C$ remarkably suppressed the viability, figration and invasion of $\mathrm{GH} 3$ cells $(\mathrm{P}<0.05$ or $\mathrm{P}<0 . \mathrm{c}$ On $\mathrm{t})$ contrary, overexpression of HULC har opposi ects, which notably enhanced the viability $\mathrm{GH} 3$ cells $(\mathrm{P}<0.05$ or $\mathrm{P}<0.0 \quad \mathrm{Fur} 2 \mathrm{~F}$ shows that TGF $-\beta$ treatment promo ${ }^{+} \mathrm{H} 3 \mathrm{C}$ migration and invasion via reducing the es ess $n$ lev of E-cadherin and enhancing the expre or of $\mathrm{N}$-cadherin, vimentin, and Snail. Comp ed to TGF- $\beta$ single treatment group, the expressior of E-Ca nerin was increased, and the expression levels o -cadherin, vimentin, and Snail were decrease in TGF- $\mathrm{p}$, reatment+sh-HULC transfection group $-\mathrm{HV}<$ transfection had opposite effects.

Morc , the esults of Figure $2 \mathrm{G}$ show that HULC $\mathrm{kr}$ own dly induced $\mathrm{GH} 3$ cell apoptosis $(\mathrm{P}<0.01)$. este $\lambda$ bloting showed that the expression levels of , cleaved-caspase 3 , and cleaved-caspase 9 i. $\mathrm{H} 3$ cells were all increased after HULC knockdown (Figur $2 \mathrm{H}$ ). Furthermore, Figure $2 \mathrm{l}$ and $\mathrm{J}$ show that HULC knockdown notably reduced the concentrations of PRL and $\mathrm{GH}$ in culture supernatant of $\mathrm{GH} 3$ cells $(P<0.05)$. On the contrary, overexpression of HULC dramatically enhanced the concentrations of PRL and $\mathrm{GH}$ in culture supernatant of $\mathrm{GH} 3$ cells $(P<0.05)$. Taken together, these results suggested that HULC exerted oncogenic roles in $\mathrm{GH} 3$ cells. Knockdown of HULC inhibit ${ }^{+} \mathrm{GH} 3$ cell viability, migration, invasion, and hormone ecre ion, but promoted cell apoptosis.

\section{HULC negatively regulated the expression of $m$} $130 \mathrm{~b}$ in $\mathrm{GH} 3$ cells

The expression level of miR-1 in $c$ ils after HULC knockdown or overexpres on was meas ared using qRT-PCR. As presented in Figi $3, \mathrm{HL} C$ knockdown enhanced the expression le of $h, 12,(P<0.01)$ and overexpression of HULC gnit th reduced the expression level of miR-130b $\quad \mathrm{H} 3$ cells $<0.05)$. This finding indicated that HULC .ega ly regulated the expression of miR-130b in $\mathrm{GH}^{-}$ells and slied that miR-130b might be involved in t' eft ts of HULC on GH3 cells.

miR-130b partic, ted in the effects of HULC on GH3 cell viar migra. $\mathrm{A}$, invasion, and apoptosis

The $t$ re: level of miR-130b in GH3 cells was increased miR-130b mimic transfection $(P<0.01)$ and decrec after miR-130b inhibitor transfection 01, Figure 4A). The results of Figure 4B-D show that LC knockdown-induced $\mathrm{GH} 3$ cell viability, migration, d invasion inhibition were markedly aggravated <-130b overexpression $(P<0.05)$ and inhibited by mir -130 b suppression $(P<0.05)$. Moreover, Figure 4E nows that HULC knockdown-induced $\mathrm{GH} 3$ cell apoptosis enhancement was also aggravated by miR-130b overexpression $(P<0.05)$ and inhibited by miR-130b suppression $(P<0.05)$. Compared to the sh-HULC + NC group, the expression levels of cleaved-PARP, cleaved-caspase 3 , and cleaved-caspase 9 in $\mathrm{GH} 3$ cells were increased in sh-HULC + miR-130b mimic group and decreased in sh-HULC + miR-130b inhibitor group (Figure 4F). These results suggested that knockdown of HULC inhibited GH3

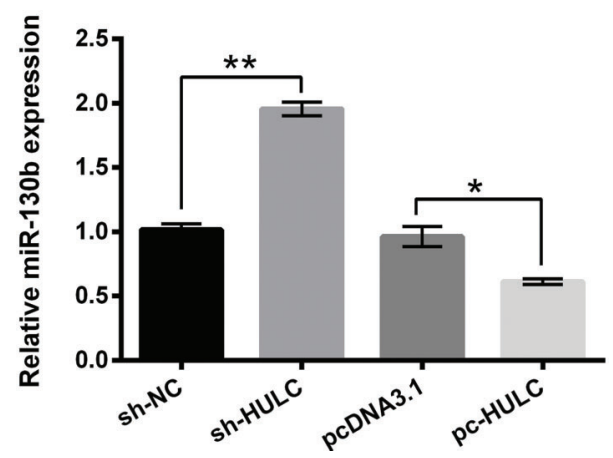

Figure 3. Highly up-regulated in liver cancer (HULC) negatively regulated the expression of miR-130b in $\mathrm{GH} 3$ cells. After shHULC or pc-HULC transfection, the expression level of miR-130b in $\mathrm{GH} 3$ cells was detected using qRT-PCR. miR-130b: MicroRNA130b; NC: negative control. Data are reported as means \pm SD. ${ }^{*} \mathrm{P}<0.05$; ${ }^{* *} \mathrm{P}<0.01$ (ANOVA). 
A

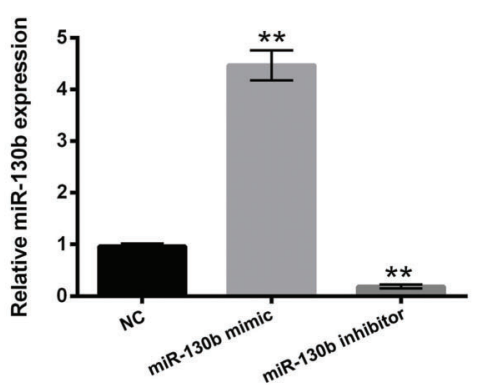

D

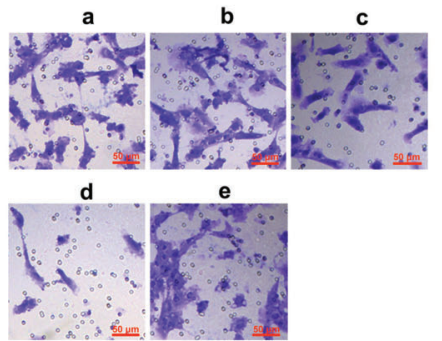

E
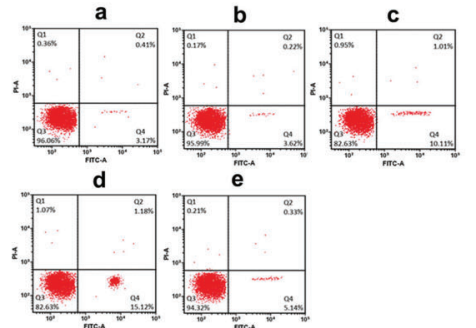

a: Control

b: $\mathbf{s h}-\mathrm{NC}+\mathrm{NC}$
B

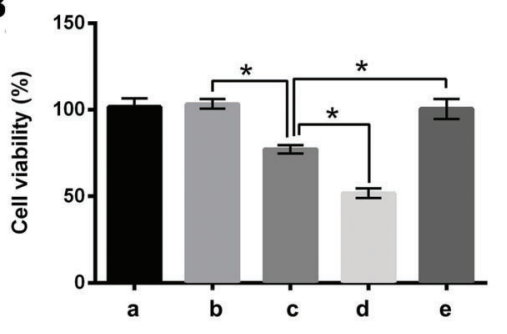

C

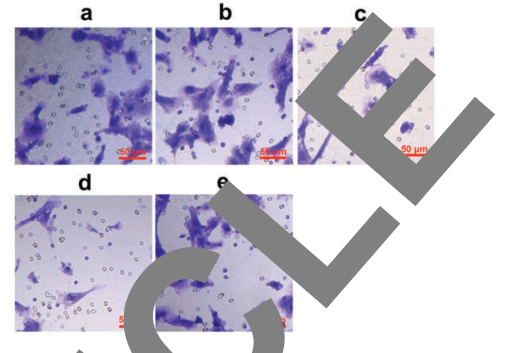

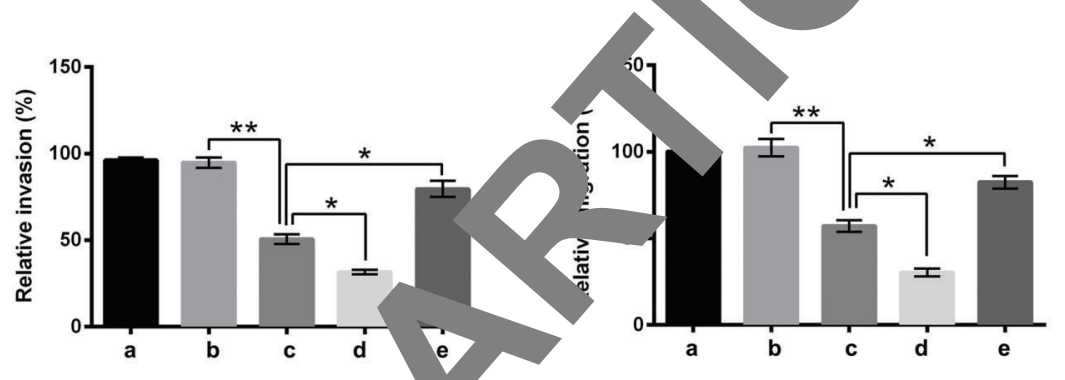

F

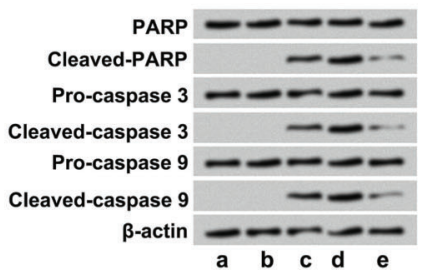

e: sh-HULC+miR-130b inhibitor

Figure 4. miR-130b participated in the effec $f$ hir up-regulated in liver cancer (HULC) on GH3 cell viability, migration, invasion, and apoptosis. A, Expression of miR-1? in GH3 Cenu arter miR-130b mimic or miR-130b inhibitor transfection was measured using qRT-PCR. After sh-HULC and/or miR-130b ml transfection, B-E, the viability, migration, invasion, and apoptosis of GH3 cells, and F, the expression levels of PARP, cleaved- ' $P$ ' pro-caspase 3, cleaved-caspase 3, pro-caspase 9, and cleaved-caspase 9 in GH3 cells were assessed using trypan blue ing a. y, two-chamber transwell assay, Guava Nexin assay, and western blotting. miR-130b: microRNA130b; NC: negative contr , PA $P$ : pol\} DP-ribose polymerase. Data are reported as means $\pm \mathrm{SD} .{ }^{*} \mathrm{P}<0.05,{ }^{* *} \mathrm{P}<0.01$ (ANOVA).

cell viability, $r$ tion, an hvasion, as well as induced GH3 cell apuptos, which might be via up-regulating $\operatorname{miR}-130$

\section{FOXM1 tare gene of miR-130b in GH3 cells}

mh a protein expression levels of FOXM1 in A3 ells atur miR-130b mimic or miR-130b inhibitor were detected in this research. As displayed in ure 5A, the mRNA and protein expression levels of FOXIn. in GH3 cells were reduced after miR-130b mimic transfection $(P<0.05$ in mRNA level) and enhanced after miR-130b inhibitor transfection ( $P<0.01$ in mRNA level). Figure $5 \mathrm{~B}$ shows that the relative luciferase activity was notably decreased after co-transfection with miR-130b mimic and FOXM1-wt $(P<0.05)$. The potential binding sequence between miR-130b and $3^{\prime}$ UTR of FOXM1 is shown in Figure $5 \mathrm{C}$. These findings indicated that miR130b negatively regulated the expression of FOXM1 and FOXM1 was a target gene of miR-130b in GH3 cells.

\section{Overexpression of FOXM1 promoted the viability, migration, and invasion of GH3 cells}

The results in Figure 6A show that pc-FOXM1 transfection increased the mRNA and protein levels of FOXM1 $(\mathrm{P}<0.01$ in mRNA level) and sh-FOXM1 transfection decreased the mRNA and protein levels of FOXM1 in GH3 cells $(P<0.01$ in mRNA level). Figure $6 B-D$ shows that the viability, migration, and invasion of $\mathrm{GH} 3$ cells were remarkably enhanced after pc-FOXM1 transfection $(\mathrm{P}<0.05$ or $\mathrm{P}<0.01)$ and reduced after sh-FOXM1 transfection 
A

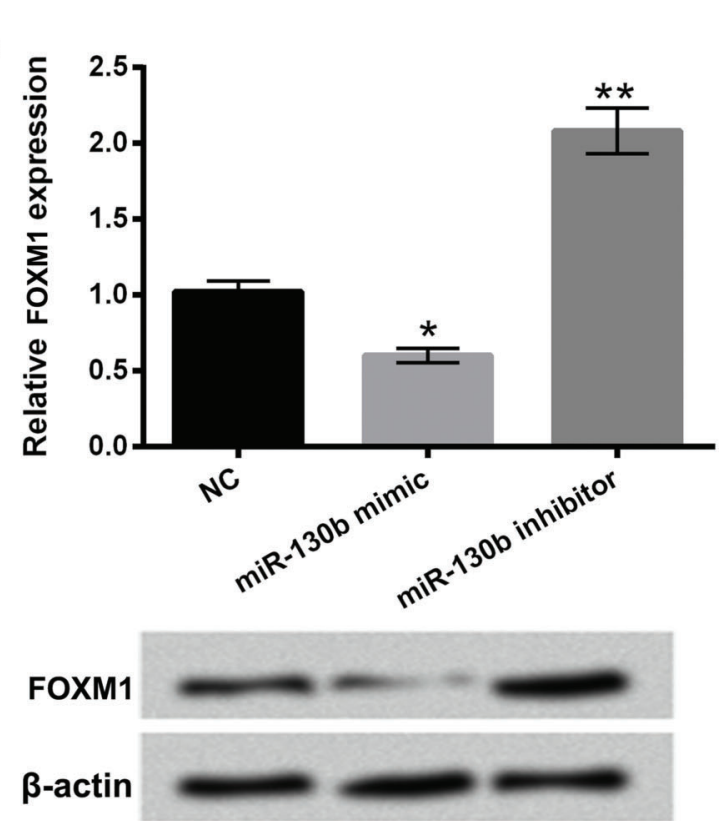

$\mathbf{B}$

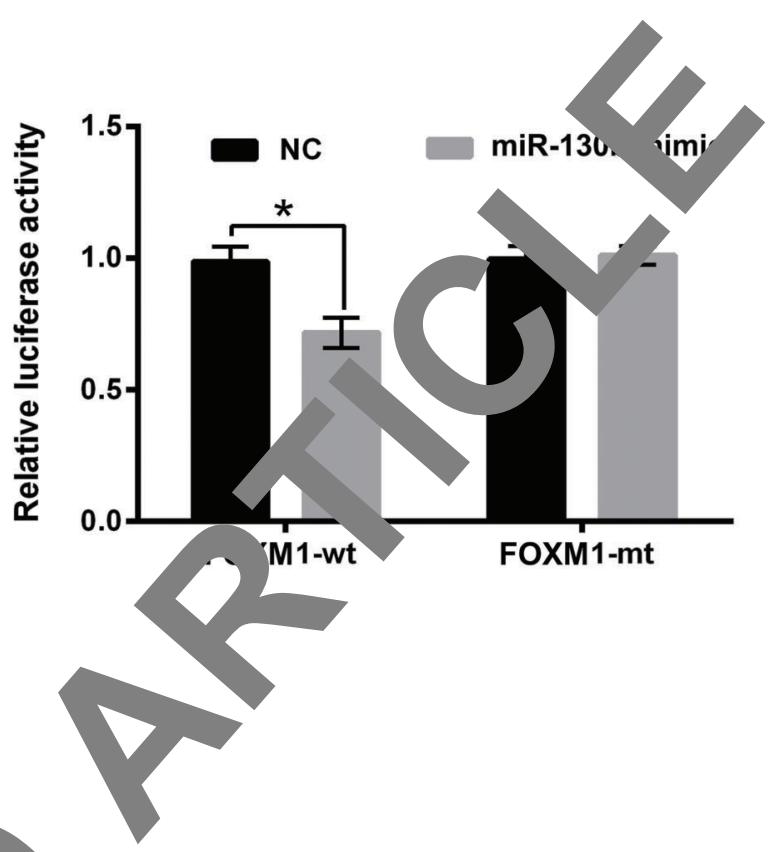

C

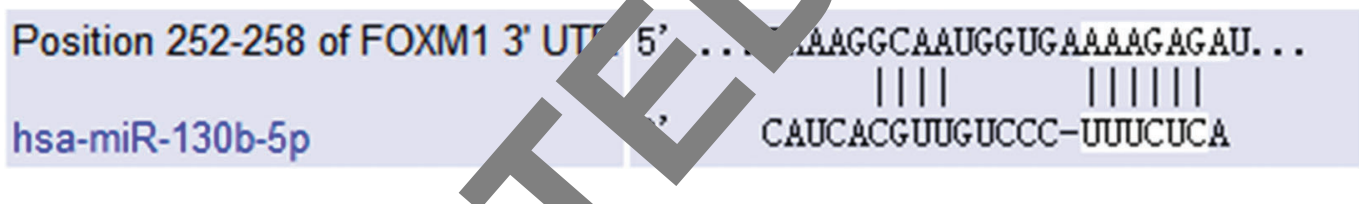

Figure 5. FOXM1 was a target gene of miR-100b in Gh, alls. A, The mRNA and protein expression levels of FOXM1 in GH3 cells after miR-130b mimic or miR-130b inh or transfection were determined using QRT-PCR and western blotting. B, Relative luciferase activities were detected after $\mathrm{c}$ (ransfec ${ }^{\prime \prime} \mathrm{n}$ with miR-130b mimic and FOXM1-wt (FOXM1-mt). C, Bioinformatics analysis was used to predict the potential binding quence etween miR-130b and $3^{\prime} U T R$ of FOXM1. miR-130b: microRNA-130b; FOXM1: forkhead box protein M1; NC: negative con . $\quad$ ild type; mt: mutated type. Data are reported as means $\pm S D$. ${ }^{*} P<0.05 ;{ }^{* *} P<0.01$ (ANOVA).

$(\mathrm{P}<0.05$ or $\mathrm{P}<0.01)$. In ditio igure $6 \mathrm{E}$ shows that sh-FOXM1 transfect' i i uced $\mathrm{GH} 3$ cell apoptosis $(P<0.01)$. Similar $r \in$ its and by western blotting, which illustrated lat expression levels of cleavedPARP, cleave' coase 3, d cleaved-caspase 9 in $\mathrm{GH} 3$ cells were aimcre ad in sh-FOXM1 transfection group (Figure $6^{5}$. These an e findings indicated that FOXM1 also pl ed cogenic roles in $\mathrm{GH} 3$ cells.

Hy ana $y, A$ participated in the regulation of $\mathrm{PI} 3 \mathrm{~K} /$ KT/r IOR and JAK1/STAT3 pathways in GH3 cells $A$ and $B$ show that overexpression of HULC ac. ted PI3K/AKT/mTOR and JAK/STAT3 pathways via up-res ating the expression rates of phosphate/total-PI3K (p/t-PIEK), p/t-AKT, p/t-mTOR, p/t-JAK1, and p/t-STAT3 in $\mathrm{GH} 3$ cells $(\mathrm{P}<0.01)$. Suppression of HULC had opposite effects, which inactivated PI3K/AKT/mTOR and JAK/STAT3 pathways via down-regulating the expression rates of p/t-PI3K, p/t-AKT, p/t-mTOR, p/t-JAK1, and p/t-STAT3 in
GH3 cells $(P<0.01)$. Moreover, Figure $7 C$ and $D$ displays that FOXM1 overexpression activated PI3K/AKT/mTOR and JAK/STAT3 pathways by enhancing the expression rates of $\mathrm{p} / \mathrm{t}-\mathrm{PI} 3 \mathrm{~K}, \mathrm{p} / \mathrm{t}-\mathrm{AKT}, \mathrm{p} / \mathrm{t}-\mathrm{mTOR}, \mathrm{p} / \mathrm{t}-\mathrm{JAK} 1$, and $\mathrm{p} / \mathrm{t}-$ STAT3 $(P<0.05$ or $P<0.01)$. Suppression of FOXM1 inactivated PI3K/AKT/mTOR and JAK/STAT3 pathways by reducing the expression rates of $\mathrm{p} / \mathrm{t}-\mathrm{PI} 3 \mathrm{~K}, \mathrm{p} / \mathrm{t}-\mathrm{AKT}$, p/t-mTOR, p/t-JAK1, and p/t-STAT3 $(P<0.05)$. Taken together, these findings suggested that HULC and FOXM1 were involved in the regulation of $\mathrm{PI} / \mathrm{K} / \mathrm{AKT} / \mathrm{mTOR}$ and JAK1/STAT3 pathways in GH3 cells and exerted oncogenic roles in $\mathrm{GH} 3$ cells, which might be via activating $\mathrm{PI} 3 \mathrm{~K} / \mathrm{AKT} / \mathrm{mTOR}$ and JAK1/STAT3 pathways.

\section{Discussion}

Pituitary adenoma comprises approximately $10-15 \%$ of all tumors in the central nervous system $(2,3,29)$. IncRNAs and miRNAs can function as oncogenes or 
A
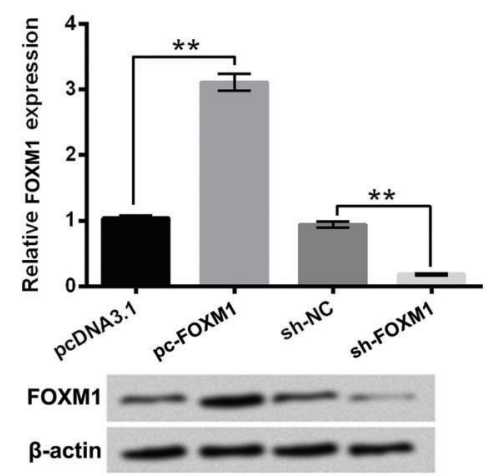

D
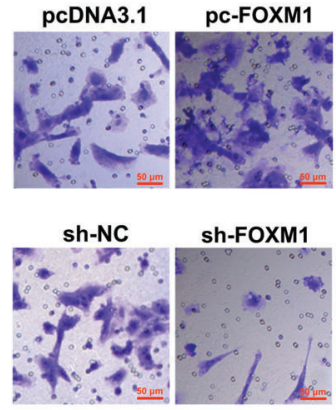

E
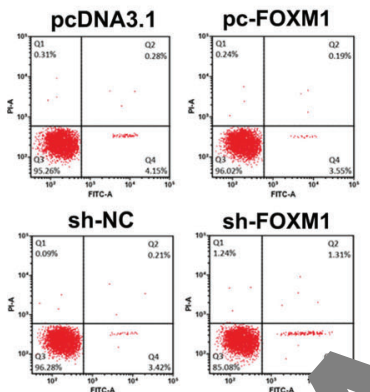

B

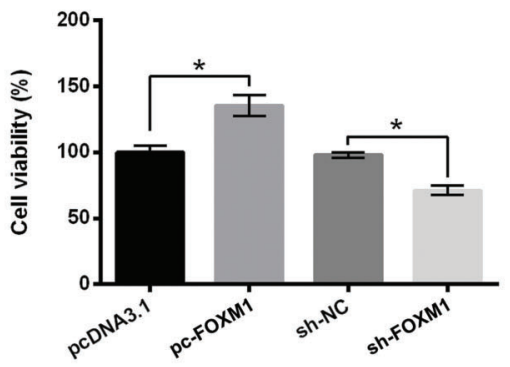

C

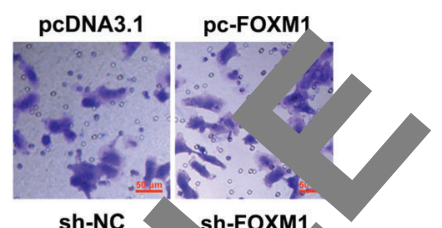

sh-NC SOXM1
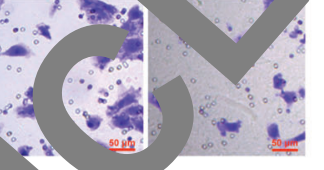

\section{(n)}

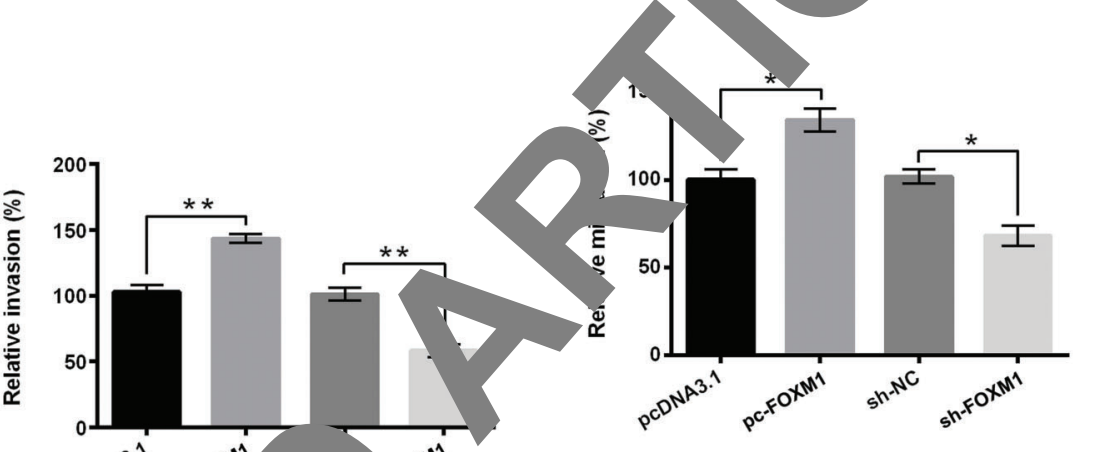

$\mathbf{F}$

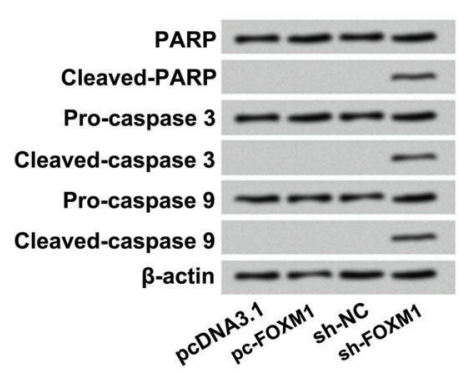

Figure 6. After pc-FOXM1 FOX transfection, A, the mRNA and protein levels of FOXM1, B-E, the viability, migration, invasion, and apoptosis of $\mathrm{GH} 3 \mathrm{C}$, an $\mathbf{F}$, the xpression levels of PARP, cleaved-PARP, pro-caspase 3, cleaved-caspase 3, pro-caspase 9, and cleaved-caspase were assessed using qRT-PCR, western blotting, trypan blue staining assay, two-chamber transwell assay, an sua exin assay. FOXM1: Forkhead box protein M1; NC: negative control; PARP: poly ADP-ribose polymerase. Data are reporter s means D. ${ }^{*} \mathrm{P}<0.05$; ${ }^{* *} \mathrm{P}<0.01$ (ANOVA).

tumor su ressors, à exert critical regulatory roles in the car logr esis of multiple cancers, including pituitary adenom, In is study, we revealed that HULC had a hi exp level in secreting pituitary adenoma A3 Ills, compared to rat pituitary primary cells. Overs com... of HULC significantly promoted the viability, mis tion, invasion, and hormone secretion of GH3 cells, as wt as down-regulated the expression of miR-130b. Knockdown of HULC had opposite effects and induced $\mathrm{GH} 3$ cell apoptosis. Furthermore, we also found that FOXM1 was a target gene of miR-130b in GH3 cells and participated in the regulation of $\mathrm{GH} 3$ cell viability, migration, invasion, and apoptosis, as well as PI3K/AKT/mTOR and JAK1/STAT3 signaling pathways.

IncRNAs do not encode proteins, but play important roles in the regulation of gene expression in cells $(9,30)$. Numerous studies have proved the oncogenic roles of HULC in cancer cells by their contribution on cancer cell proliferation and metastasis $(13,15)$. For example, Chen et al. (14) reported that overexpression of HULC promoted proliferation, migration, and invasion of epithelial ovarian carcinoma cells. Matouk et al. (31) indicated that HULC was related to metastasis of colorectal carcinomas. Our results were consistent with previous studies. 
A

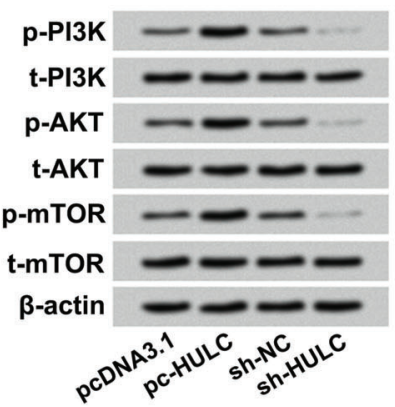

B

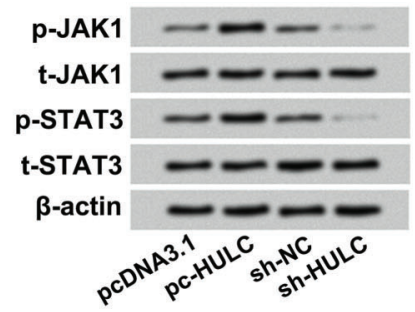

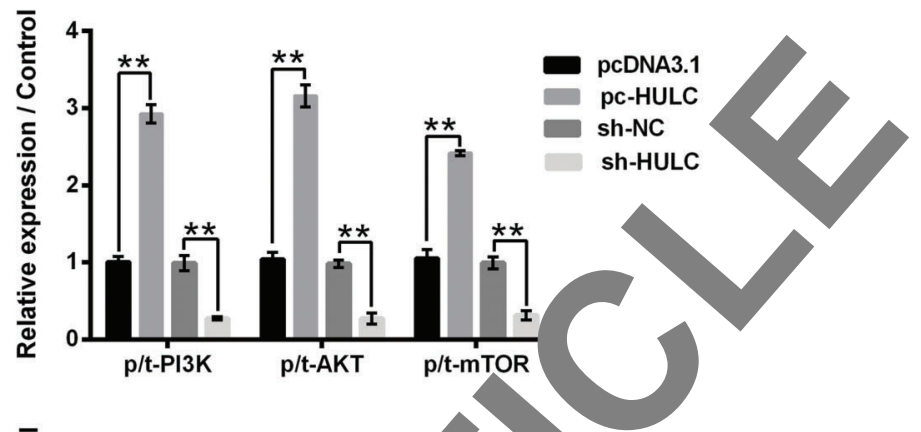

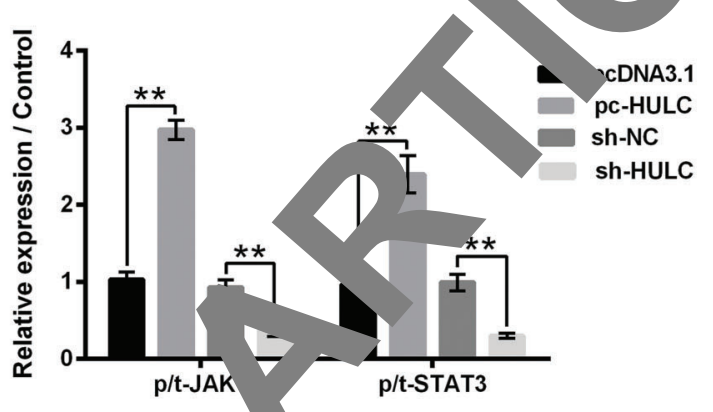
C

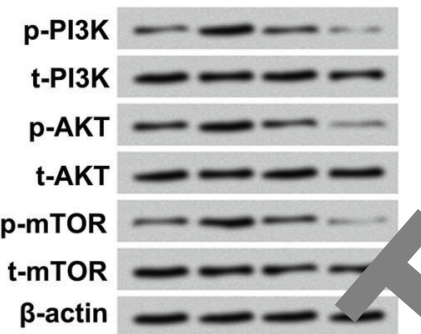

\section{D}
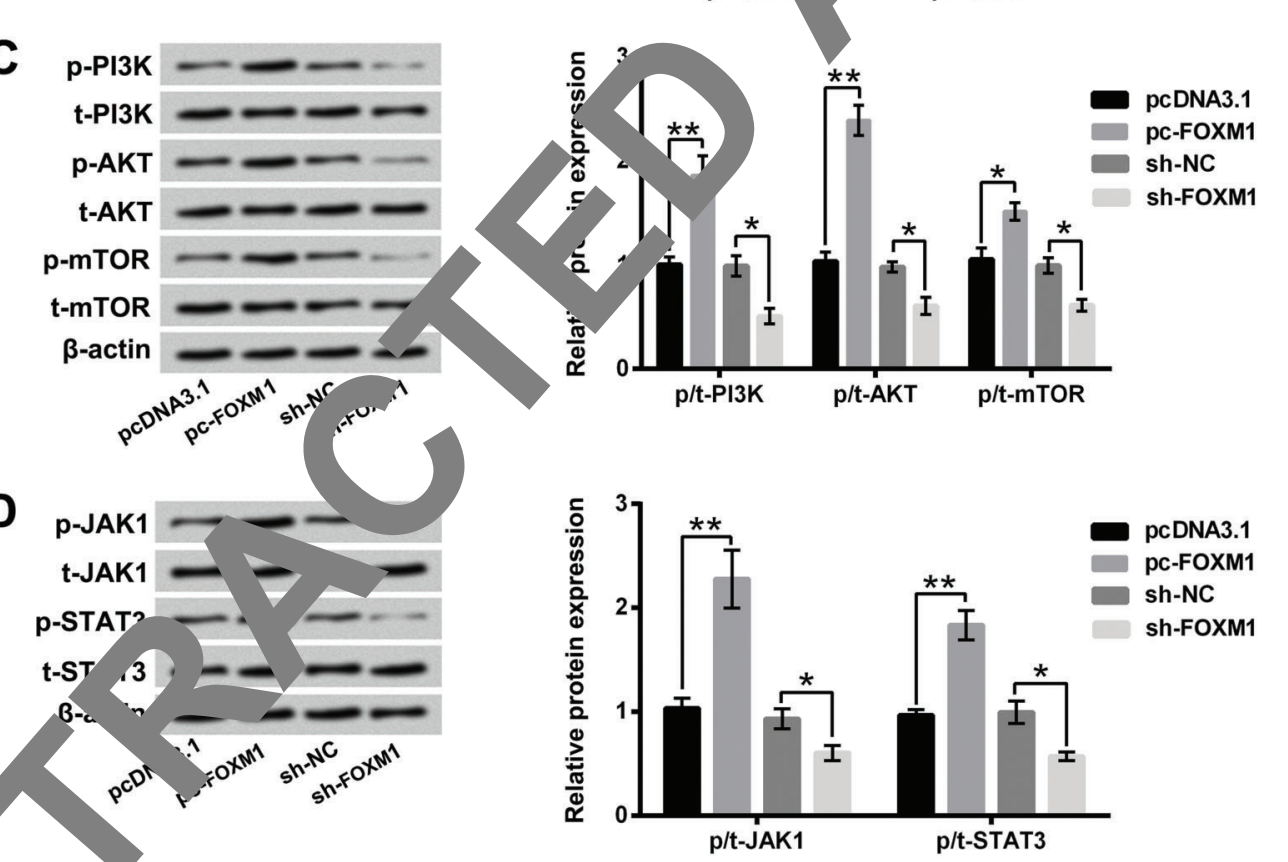

Figure Dy expre sion of FOXM1 activated PI3K/AKT/mTOR and JAK1/STAT3 pathways in GH3 cells. (A and B) The expression levelc of $3 \mathrm{~K}, \quad 3 \mathrm{~K}, \mathrm{p}-\mathrm{AKT}$, t-AKT, p-mTOR, t-mTOR, p-JAK1, t-JAK1, p-STAT3, and t-STAT3 in GH3 cells after pc-HULC or $S^{\prime}$, tran won were evaluated using western blotting. (C and D) The expression levels of the same proteins in GH3 cells after c-FO, 11 or sn-FOXM1 transfection were evaluated using western blotting. HULC: Highly up-regulated in liver cancer; FOXM1: , au wo protein M1; NC: negative control; PI3K: phosphatidylinositol 3-kinase; AKT: protein kinase 3; mTOR: mammalian target of rap vcin; JAK1: janus kinase 1; STAT3: signal transducing activator of transcription 3. Data are reported as means $\pm S D$. ${ }^{*}<<0.05$; ${ }^{* *} \mathrm{P}<\mathrm{V}$ (ANOVA).

Abnormal hormone secretion is one of the major complications of secreting pituitary adenomas (32). As a rat secreting pituitary adenoma cell line, $\mathrm{GH} 3$ can also secret PRL and GH (33). Therefore, we also assessed the $\mathrm{PRL}$ and $\mathrm{GH}$ levels in culture supernatant of $\mathrm{GH} 3$ cells after HULC overexpression or knockdown. Taken together, 
our results revealed the critical roles of HULC in regulating rat secreting pituitary adenoma cell proliferation, metastasis, and hormone secretion.

One of the most important findings in this research was that HULC negatively regulated the expression of miR-130b in GH3 cells. Reports have proved that miRNAs are involved in the regulation of intracellular gene expression at the post-transcriptional level $(19,34)$. miR-130b has been demonstrated to be down-regulated in pituitary adenomas cells, including secreting pituitary adenoma (22). The findings of the present study suggested that HULC exerted oncogenic roles in rat secreting pituitary adenoma $\mathrm{GH} 3$ cells at least in part by down-regulating miR-130b.

As a typical cell proliferation-associated transcription factor, FOXM1 plays important roles in regulating cell proliferation (35). Moreover, FOXM1 has a high expression level in many human cancer cells $(24,36)$. In this study, we revealed that FOXM1 was a target gene of miR$130 \mathrm{~b}$ in $\mathrm{GH} 3$ cells. The findings indicated that miR-130b participated in the effects of HULC on $\mathrm{GH} 3$ cells, which might be through regulating FOXM1.

PI3K/AKT/mTOR and JAK1/STAT3 signaling pathways play critical roles in the regulation of multiple cell

\section{References}

1. Vender JR, Laird MD, Dhandapani KM. Inhir kappaB reduces cellular viability in $\mathrm{GH} 3$ pity v adeno cells. Neurosurgery 2008; 62: 1122-1127; cus n 10271128, doi: 10.1227/01.neu.0000325874.82999.75.

2. Ogando-Rivas E, Alalade AF, Bo2 J, Schwart TH. Double pituitary adenomas are mos common' associated with $\mathrm{GH}$ - and ACTH-secreting tumol system review of the literature. Pituitary 2017: 20: 70 s11102-017-0826-6.

3. Rieken S, Habermehl D, Welz T, M Zindel K, Debus J, et al. Long term toxicity and $p$ sstic factors of radiation therapy for secretine $\pi$ on-se ting pituitary adenomas. Radiation oncolog J13; 18 dol 10.1186/1748-717X-8-18.

4. Lake MG, Krook overview. Ar am $P_{h}$, vian 2013; 88: 319-327.

5. Asa SL, M Immun , stochemical biomarkers in pituitary pathuogy. 'vor Pathol 2018; 29: 130-136, doi: 10. 1007/ 2022-018- 1-z.

6. Pe DI Burke WT, Laws ER. Management of nonfü or g pity ary adenomas: surgery. Pituitary 2018; 21: 14- do $10.1007 / \mathrm{s} 11102-017-0854-2$.

(s) tzer J, iton CE, Scotton TC, Pangal D, Carmichael JD, Gene and protein expression in pituitary corticoroph adenomas: a systematic review of the literature. surosurg Focus 2015; 38: E17, doi: 10.3171/2014.10. PUCUS14683.

8. Spoletini M, Taurone S, Tombolini M, Minni A, Altissimi G, Wierzbicki $V$, et al. Trophic and neurotrophic factors in human pituitary adenomas (review). Int $J$ Oncol 2017; 51: 1014-1024, doi: 10.3892/ijo.2017.4120. functions, such as cell proliferation, cell invasion, and cell apoptosis $(37,38)$. Tian et al. (39) proved that miF $61-5 p$ inhibited chemo-resistance of gastric cance cell by targeting FOXM1 and PI3K/AKT/mTOR sig "n path way. Buslei et al. (40) reported that the activation IAV STAT3 signaling pathway contributed to the develop ant of pituitary adenoma. Thus, in this resea we al analyzed the effects of HULC and FC 1 or tivation of PI3K/AKT/mTOR and JAK1/S AT3 pathways in GH3 cells. The results suggested that $\mathrm{LLC}$ ex ted oncogenic roles in $\mathrm{GH} 3$ cells, which ht own-regulating miR-130b, up-regulating $F \quad X M$. nd then activating PI3KJ AKT/mTOR and JAK1/ T3 path ys.

In summary, our sea verified the oncogenic roles of HULC in rat so pling plu adenoma GH3 cells. This study cor out ; to the further understanding of the pathoger ang pituitary adenomas and is helpful for defin. potential diagnostic and therapeutic targets.

\section{Acknow} gments

This work was supported by Key Subjects of Ningbo No. . lospital (2016-57).

9. Noh JH, Kim KM, McClusky WG, Abdelmohsen K, Gorospe M. Cytoplasmic functions of long noncoding RNAs. Wiley Interdiscip Rev RNA 2018; 9: e1471, doi: 10.1002/wrna.1471.

10. DiStefano JK. The Emerging Role of Long Noncoding RNAs in Human Disease. Methods in molecular biology (Clifton, N.J.) 2018; 1706: 91-110.

11. Li Z, Li C, Liu C, Yu S, Zhang Y. Expression of the long non-coding RNAs MEG3, HOTAIR, and MALAT-1 in non-functioning pituitary adenomas and their relationship to tumor behavior. Pituitary 2015; 18: 42-47, doi: $10.1007 /$ s11102-014-0554-0.

12. Xiong $\mathrm{H}$, Li B, He J, Zeng $\mathrm{Y}$, Zhang $\mathrm{Y}$, He F. IncRNA HULC promotes the growth of hepatocellular carcinoma cells via stabilizing COX-2 protein. Biochem Biophys Res Commun 2017; 490: 693-699, doi: 10.1016/j.bbrc.2017.06.103.

13. Sun XH, Yang LB, Geng XL, Wang R, Zhang ZC. Increased expression of IncRNA HULC indicates a poor prognosis and promotes cell metastasis in osteosarcoma. Int $J$ Clin Exp Pathol 2015; 8: 2994-3000.

14. Chen $\mathrm{S}$, Wu DD, Sang XB, Wang LL, Zong ZH, Sun KX, et al. The IncRNA HULC functions as an oncogene by targeting ATG7 and ITGB1 in epithelial ovarian carcinoma. Cell Death Dis 2017; 8: e3118, doi: 10.1038/cddis.2017.486.

15. Wang J, Ma W, Liu Y. Long non-coding RNA HULC promotes bladder cancer cells proliferation but inhibits apoptosis via regulation of ZIC2 and PI3K/AKT signaling pathway. Cancer Biomark 2017; 20: 425-434, doi: 10.3233/CBM170188.

16. Yan $H$, Tian $R$, Zhang $M, W u ~ J$, Ding $M$, He J. High expression of long noncoding RNA HULC is a poor predictor 
of prognosis and regulates cell proliferation in glioma. Onco Target Ther 2017; 10: 113-120, doi: 10.2147/OTT.S124614.

17. Shi F, Xiao F, Ding P, Qin H, Huang R. Long noncoding RNA highly up-regulated in liver cancer predicts unfavorable outcome and regulates metastasis by MMPs in triplenegative breast cancer. Arch Med Res 2016; 47: 446-453, doi: 10.1016/j.arcmed.2016.11.001.

18. Lu Y, Li Y, Chai X, Kang Q, Zhao P, Xiong J, et al. Long noncoding RNA HULC promotes cell proliferation by regulating PI3K/AKT signaling pathway in chronic myeloid leukemia. Gene 2017; 607: 41-46, doi: 10.1016/j.gene.2017.01.004.

19. Klinge CM. Non-coding RNAs: long non-coding RNAs and microRNAs in endocrine-related cancers. Endocr Relat Cancer 2018; 25: R259-R282, doi: 10.1530/ERC-17-0548.

20. Pawlowska E, Szczepanska J, Blasiak J. The long noncoding RNA HOTAIR in breast cancer: does autophagy play a role? Int J Mol Sci 2017; 18: pii: E2317, doi: 10.3390/ ijms18112317.

21. Xiao ZQ, Yin TK, Li YX, Zhang JH, Gu JJ. miR-130b regulates the proliferation, invasion and apoptosis of glioma cells via targeting of CYLD. Oncol Rep 2017; 38: 167-174, doi: 10.3892/or.2017.5651.

22. Leone $\mathrm{V}$, Langella $C$, D'Angelo $D$, Mussnich $P$, Wierinckx A, Terracciano $L$, et al. Mir-23b and miR-130b expression is downregulated in pituitary adenomas. $\mathrm{Mol} \mathrm{Cel} \mathrm{Endocrinol}$ 2014; 390: 1-7, doi: 10.1016/j.mce.2014.03.002.

23. Wierstra I, Alves J. FOXM1, a typical proliferation-associatec. transcription factor. Biol Chem 2007; 388: 1257-1 4, doi: 10.1515/BC.2007.159.

24. Pratheeshkumar P, Divya SP, Parvathareddy SK, $R$ sh NM, Al-Badawi IA, Tulbah A, et al. FoxM1 and $r$ predicts aggressiveness in Middle Eastern $c$ rian can and their co-targeting impairs the growth $\mathrm{C} \mathrm{JV}_{\mathrm{c}} \mathrm{n}$ cancer cells. Oncotarget 2017; 9: 3590-3604.

25. Poudyal D, Herman A, Adelsberger JV .ing J, Hu X, chen $Q$, et al. A novel microRNA, hsa iR-6852 vifferentially regulated by Interleukin-27 induce necrosis n cervical cancer cells by downregulating the $\mathrm{Fo}_{\mathrm{C}}$ ression. Sci Rep 2018; 8: 900, doi: 10.1 1598-018-19259-4.

26. Okato A, Arai T, Yamada Y Sugr S, Koshizuka K, Fujimura L, et al. Dual strands -miR-149 inhibit cancer cell migration and $n$th gh targeting FOXM1 in renal cell carcinor. Int Mol Sc, 2017; 18: pii E1969, doi: 10.3390/ijms1809

27. Ish-Shalom $S$ - Achte Analysis of fungal gene expression by real tim ntitative R. Methods Mol Biol 2010; 638: 103-114, Uoi: $907 / 978-1-60761-611-5$.

28. Li R, F, Guo Y, hao KC, Ruan Q, Qi YM. Knockdown of $\mathcal{R}$ gravates $\mathrm{H} 2 \mathrm{O} 2$-induced injury in $\mathrm{PC}-12$ cells by targeting microRNA-125a. Biomed Pharmacother 2017; 92: 952-961, doi: 10.1016/j.biopha.2017.05.122.

29. Theodros D, Patel M, Ruzevick J, Lim M, Be' jow na C. Pituitary adenomas: historical perspective, sur al $\mathrm{n}$ agement and future directions. CNS oncology 2015; doi: $10.2217 / \mathrm{cns} .15 .21$

30. Chen L, Dzakah EE, Shan G. Target long non-coding RNAs in cancer treatments. Cancer Lett 2 418 .9-124, doi: 10.1016/j.canlet.2018.01.042

31. Matouk IJ, Abbasi I, Hochbe A, Galan E, Dweik H, Akkawi M. Highly upregulated in er canc noncoding RNA is overexpressed in hepa col etastasis. Eur $J$ Gastroenterol Hepatol J09, 688-692, doi: 10.1097/ MEG.0b013e32830f э2.

32. Mehta GU, Lonse R. nagement of hormone-secreting pituitary adenomas. Neuro col 2017; 19: 762-773, doi: 10.1093 /neur $\mathrm{min} 130$.

33. Tamura $\mathrm{N}$ ahar , Kuwahara $\mathrm{A}$, Ushigoe $\mathrm{K}$, Sugino $\mathrm{H}$, Aono $T$. El activm on production and secretion of prolactin and 9 , th hormone in cultured rat GH3 cells. Eur $J E$ I 200 142: 506-511, doi: 10.1530/eje.0.142 0506 .

34. Hamm sM. An overview of microRNAs. Adv Drug Deliv Rev 20 1 87: 3-14, doi: 10.1016/j.addr.2015.05.001.

Iaoukili J, Stahl M, Medema RH. FoxM1: At the crossroads ageing and cancer. Biochim Biophys Acta 2007; 1775: 102, doi: 10.1016/j.bbcan.2006.08.006.

guchi S, Seki N, Chiyomaru T, Ishihara T, Matsushita R, lataki $\mathrm{H}$, et al. Tumour-suppressive microRNA-24-1 inhibits cancer cell proliferation through targeting FOXM1 in bladder cancer. FEBS letters 2014; 588: 3170-3179, doi: 10.1016/ j.febslet.2014.06.058.

37. Ramakrishnan V, Kumar S. PI3K/AKT/mTOR pathway in multiple myeloma: from basic biology to clinical promise. Leuk Lymphoma 2018; 1-11, doi: 10.1080/10428194.2017. 1421760.

38. Cornez I, Yajnanarayana SP, Wolf AM, Wolf D. JAK/STAT disruption induces immuno-deficiency: Rationale for the development of JAK inhibitors as immunosuppressive drugs. Mol Cel Endocrinol 2017; 451: 88-96, doi: 10.1016/ j.mce.2017.01.035.

39. Tian L, Zhao Z, Xie L, Zhu J. MiR-361-5p suppresses chemoresistance of gastric cancer cells by targeting FOXM1 via the PI3K/Akt/mTOR pathway. Oncotarget 2017; 9: 48864896.

40. Buslei R, Kreutzer J, Hofmann B, Schmidt V, Siebzehnrubl $\mathrm{F}$, Hahnen E, et al. Abundant hypermethylation of SOCS-1 in clinically silent pituitary adenomas. Acta Neuropathol 2006; 111: 264-271, doi: 10.1007/s00401-005-0009-9. 